\title{
Regional modeling of atmospheric mercury: impact of meteorological variables
}

\author{
$\underline{\text { V. Matthias }}^{1}$, A. Aulinger ${ }^{1}$, J. Bieser $^{1}$ and M. Quante $^{1}$ \\ ${ }^{1}$ Department for Environmental Chemistry, Institute of Coastal Research, Helmholtz-Zentrum Geestacht, 21502 \\ Geesthacht, Germany, volker.matthias@hzg.de
}

\begin{abstract}
The atmospheric mercury concentration in Europe was simulated with the regional atmospheric chemistry transport model CMAQ-Hg. Two sets of meteorological fields, one from MM5 and one from COSMO-CLM (CCLM) were used to drive the model. The results differ significantly, in particular gaseous elemental mercury $(\mathrm{Hg} 0)$ concentrations are much lower in the run with meteorological fields from MM5 compared to the run with CCLM meteorology. Looking at the mercury sinks within the model domain, it was found that dry deposition of $\mathrm{Hg} 0$ is the main sink in both model runs. Remarkably, dry deposition velocities are much higher when calculated with MM5 meteorological fields. Wet deposition of oxidized mercury is a factor of 5-6 lower than dry deposition of $\mathrm{Hg} 0$. In CMAQ with MM5 meteorology wet deposition is about a factor of two higher compared to the run with CCLM.
\end{abstract}

Key words: mercury, chemistry transport modeling, deposition, meteorological fields

\section{Introduction}

Mercury is a global pollutant. Its lifetime in the atmosphere is about a year, therefore it can be transported over large distances. Regional modeling of atmospheric mercury requires input of mercury concentration fields at the lateral boundaries from global or hemispheric models. Due to the long lifetime of atmospheric mercury, the boundary conditions typically dominate the mercury concentrations within a limited area. However, regional models may give a better representation of mercury concentrations close to sources or sinks thanks to their higher spatial and temporal resolution.

In the EU FP7 project Global Mercury Observation System (GMOS), global and regional models are tested with respect to their different chemical mechanisms, the coupling of global to regional models and the impact of sources (emissions) and sinks (depositions) on the atmospheric mercury concentrations.

Here, we investigate the effect of different meteorological fields on transport and deposition of mercury in Europe.

\section{Methods}

Two mesoscale meteorological models, namely MM5 (Grell et al, 1995) and COSMO CLM (CCLM) (Schättler et al., 2008, Rockel et al., 2008) were used as input for the regional chemistry transport model CMAQ (Byun and Ching, 1999, Byun and Schere, 2006) in its version including mercury (CMAQ-Hg) (Bullock and Brehme, 2002).

The models were run on a $54 \mathrm{~km}$ x $54 \mathrm{~km}$ grid with $90 \times 81$ grid cells covering entire Europe. Thirty vertical layers up to $100 \mathrm{hPa}$ ensure a good vertical resolution of the meteorological fields, including the boundary layer. MM5 was driven with ERA40 reanalysis fields, CCLM was driven with NCEP2 reanalysis. In both models nudging techniques (four dimensional data assimilation (FDDA) in MM5 and spectral nudging in CCLM) were used to keep the model as close to the observed meteorological fields as possible.

CMAQ-Hg was used in version 4.6 with carbon bond 4 (CB4) chemical mechanism (Gery et al., 1989) and including aerosol chemistry. Important species like ozone, $\mathrm{OH}$ radicals and sulphur dioxide are calculated explicitly. Mercury chemistry considers gaseous elemental mercury $(\mathrm{Hg} 0)$, oxidised mercury (HgII) and particle bound mercury $(\mathrm{HgP})$. Chemical reactions include oxidation of mercury with ozone and $\mathrm{OH}$.

Lateral boundary conditions were taken from ECHMERIT (Jung et al., 2009) global model runs. In total 40 species are transported from the boundaries into the model domain. Besides the mercury species $\mathrm{Hg} 0$, $\mathrm{HgII}$ and $\mathrm{HgP}$, ozone, nitrogen oxides, sulphur doxide and numerous organic compounds are prescribed at the boundaries. 
Emissions were calculated with the SMOKE-EU model (Bieser et al., 2011). SMOKE-EU distributes annual totals from EMEP (for area sources) and EPER (for point sources) in time and space over the entire model domain. Annual totals for mercury were taken from Pacyna et al. (2010).

The model was run for 2 months, May and June 2000. The first month was not considered in the evaluation because a spinup time of one month is needed until the model results become independent of the initial conditions.

\section{Results and Discussion}

$\mathrm{Hg} 0$ concentrations in Europe were considerably different in both model runs. While the mean $\mathrm{Hg} 0$ levels in central Europe were between 1.5 and $1.7 \mathrm{ng} / \mathrm{m}^{3}$ in the CMAQ run with CCLM meteorological fields, the concentrations were considerably lower in the run with MM5 meteorological fields. Here, the mean $\mathrm{Hg} 0$ concentrations were only about 1.1 to $1.4 \mathrm{ng} / \mathrm{m}^{3}$ (see Figure 1). The largest part of the mercury load is transported via the boundaries into the model domain. This can clearly be seen at the western boundary where the high mercury load that is transported eastwards reaches much deeper into the domain in the CMAQ/CCLM run.

In the model, mercury may be converted into reactive gaseous mercury (here considered as oxidized mercury HgII) or particulate mercury. Both forms of reactive mercury have much lower concentrations in the atmosphere as $\mathrm{Hg} 0$ (more than a factor of 10). The only mercury sinks in the model are wet and dry deposition. According to the model results dry deposition is the most important mercury sink. In CMAQ/CCLM five times more mercury is lost by dry deposition than by wet deposition in the entire domain in June 2000. For CMAQ/MM5 the ratio of dry to wet deposition is about six.

Wet deposition is dominated by losses in HgII and $\mathrm{HgP}$, both in the same order of magnitude. Figure 2 shows the simulated fields for HgII for both model configurations. The CMAQ/MM5 run shows higher wet deposition in central and eastern Europe and at the border of the Norwegian west coast.

The largest differences between the model runs can be seen in $\mathrm{Hg} 0$ dry deposition (Fig. 3). Dry deposition strongly depends on surface roughness. Therefore it is much higher over land than over water. The CMAQ/MM5 run shows considerable dry deposition of $\mathrm{Hg} 0$ also over water while it is very low in the CMAQ/CCLM run. The regional pattern of the dry deposition shows high values in central Europe and low values in Scandinavia, Turkey and Africa. CMAQ/MM5 has much higher dry deposition compared to CMAQ/CCLM also over land.

The magnitude of the difference between the dry deposition values for the model runs with different meteorological fields is surprisingly high. It is probably one important reason for the different $\mathrm{Hg} 0$ concentrations in the two simulations. Additional investigations of the deposition scheme in CMAQ and its dependence on the meteorological input variables are necessary to identify the reasons for these differences in the model results. This includes the additional consideration of WRF (Skamarock and Klemp, 2008) meteorological fields as input for CMAQ and comparisons to observations of both, $\mathrm{Hg}$ concentrations and $\mathrm{Hg}$ deposition.
Hg0 concentration

June 2000, CCLM meteo
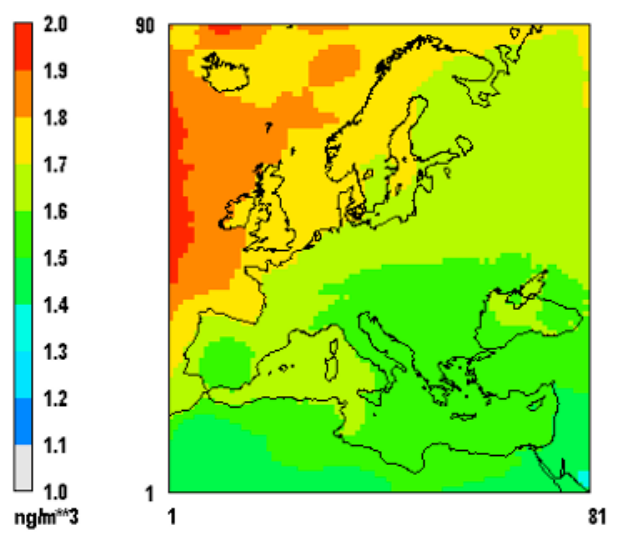

Hg0 concentration June 2000, MMM5 meteo
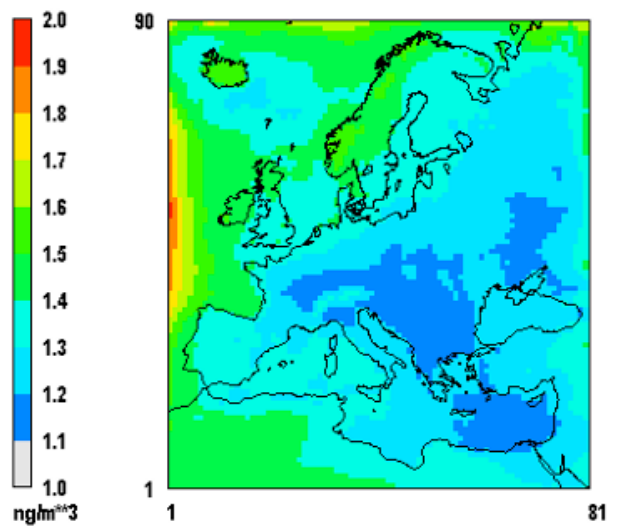

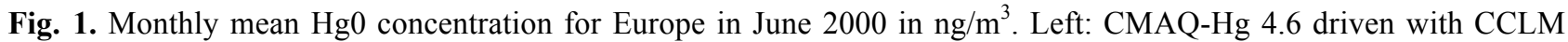
meteorological fields. Right: same as left but with MM5 meteorological fields. 
HgII wet deposition

totals June 2000, CCLM meteorology
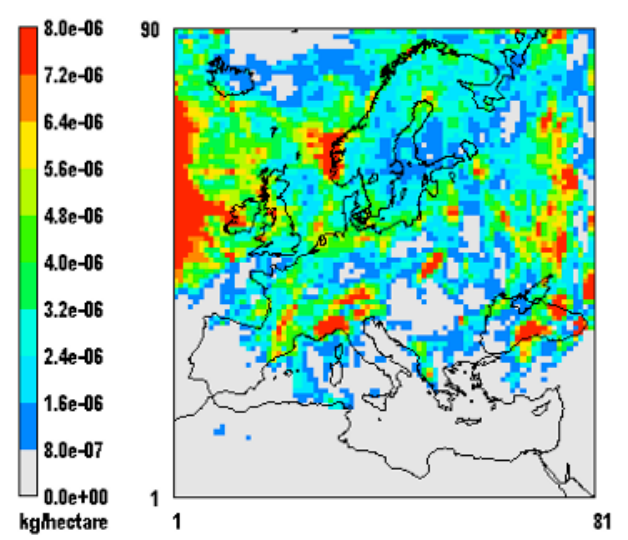

HgII wet deposition

totals June 2000, MMS5 meteorology
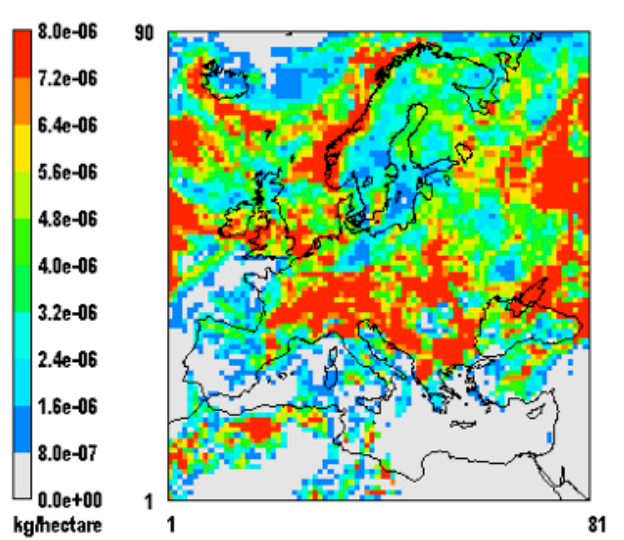

Fig. 2. Monthly total HgII wet deposition for Europe in June 2000 in $\mathrm{kg} /$ hectare. Left: CMAQ-Hg 4.6 driven with CCLM meteorological fields. Right: same as left but with MM5 meteorological fields.

Hg0 dry deposition

totals June 2000, CCLM meteorology
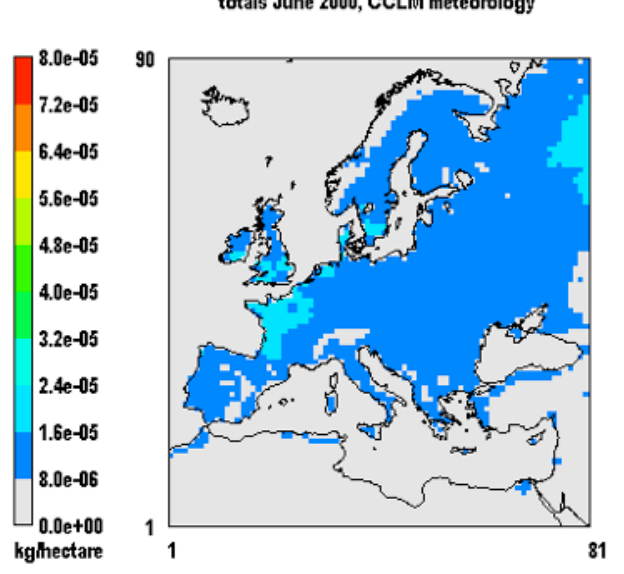

81

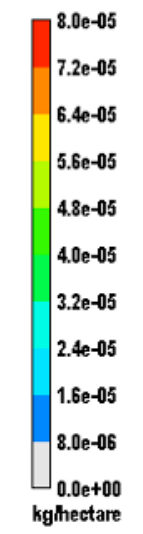

Hg0 dry deposition

totals June 2000, MMA5 meteorology

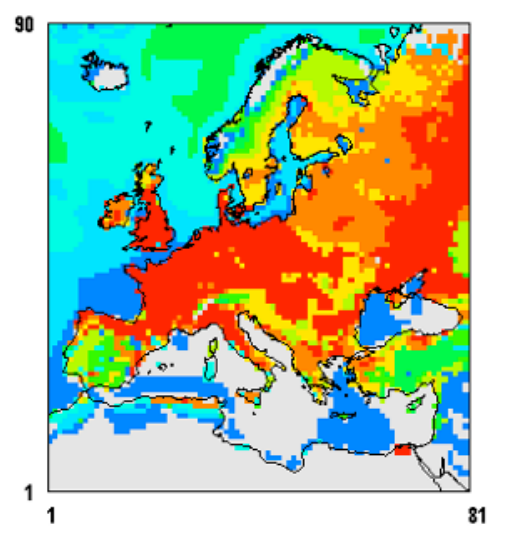

Fig. 3. Monthly total $\mathrm{Hg} 0$ dry deposition for Europe in June 2000 in $\mathrm{kg} /$ hectare. Left: CMAQ-Hg 4.6 driven with CCLM meteorological fields. Right: same as left but with MM5 meteorological fields.

\section{Conclusion}

Meteorological fields used to drive the regional atmospheric chemistry model CMAQ appeared to have a big impact on the model results of mercury concentrations in Europe. Two CMAQ model runs with meteorological fields from either CCLM or MM5 were used to simulate mercury concentrations in one month, here June 2000. Differences of 0.4 to $0.5 \mathrm{ng} / \mathrm{m}^{3}$ in $\mathrm{Hg} 0$ concentrations close to ground were found although both model runs had the same boundary conditions for $\mathrm{Hg} 0$, $\mathrm{HgII}$ and $\mathrm{HgP}$.

One important difference between the model runs was the mercury deposition. In particular dry deposition of $\mathrm{Hg} 0$ was much higher in the CMAQ/MM5 simulation compared to CMAQ/CCLM. The reasons for these unexpected results need to be looked at in detail. This includes a comparison of the model results to observations and the testing of the model with regard to the underlying algorithms including another set of meteorological fields from WRF.

\section{Acknowledgements}

This work was done in the framework of the EU FP7 project Global Mercury Observation system (GMOS). GMOS is supported by the European Commission under grant agreement 265113.

CMAQ has been developed by the US EPA. The use of CMAQ is gratefully acknowledged

MM5 has been developed by NCAR and Penn State University. The authors thank the developers for the possibility to use the model. 


\section{References}

Bieser, J., Aulinger, A., Matthias, V., Quante, M., Builtjes, P., 2011. SMOKE for Europe - adaption, modification and evaluation of a comprehensive emission model for Europe. GeoSci. Model Dev. 4, $1-22$

Bullock, O.R., Jr. and Brehme, K.A., 2002. Atmospheric Atmospheric mercury simulation using the CMAQ model: formulation description and analysis of wet deposition results. Atmos. Environ. 36, 2135-2146

Byun D., Ching J.K.S., 1999. Science Algorithms of the EPA Models-3 Community Multiscale Air Quality Modelling System. EPA report, EPA/600/R-99/030. Office of Res. and Developm, Washington, DC, USA.

Byun, D.W. and Schere, K.L., 2006. Review of the governing governing equations, computational algorithms, and other components of the Models-3 community Multiscale Air Quality (CMAQ) modeling system, Appl. Mech. Rev., 59(2), 51-77

Gery, M.W., Whitten, G.Z., Killus, J.P., Dodge, M.C., 1989. A photochemical kinetics mechanism for urban and regional scale computer modeling. J. Geophys. Res. 94, 12925 - 12956.

Grell, G., Dudhia, J., and Stauffer, D.R., 1995. A
Description of the Fifth-Generation Penn State/NCAR Mesoscale Model (MM5). NCAR Technical Note 398, NCAR, Boulder, Colorado, USA.

Jung, G., Hedgeckock, I.M., Pirrone, N., 2009. ECHMERIT V1.0 - a new global fully coupled mercurychemistry and transport model. Geosci. Model Dev. 2, 175-195

Pacyna, E., Pacyna, J., Sundseth, K., Munthe, J., Kindbom, K., Wilson, S., Steenhuisen, F., Maxson, P., 2010. Global emission of mecury to the atmosphere from anthropogenic sources in 2005 and projections to 2020. Atmos. Environ. 4, 2487-2499

Rockel, B., Will, A. and Hense, A. (2008): The regional climate model COSMO-CLM (CCLM), Meteorol. Z., 17, 347-248

Schättler, U., Doms, G., Schraff, C., 2008. A description of the nonhydrostatic regional COSMO-Model. Part I: Dynamics and numerics. Deutscher Wetterdienst, Offenbach, 2008 [available from http://www.cosmo-model.org].

Skamarock ,W.C., Klemp, J.B., 2008. A Time-Split Nonhydrostatic Atmospheric Model for Weather Research and Forecasting Applications. J. Comp. Phys. 227, 3465-3485. 